\title{
Esbozos etnográficos sobre la migración entre los mayas peninsulares de Campeche
}

\author{
David DE ÁNGEL GARCÍA \\ Centro Peninsular en Humanidades y en Ciencias Sociales \\ Universidad Nacional Autónoma de México \\ corle_spck@yahoo.es
}

Recibido: $14 / 12 / 2015$

Aceptado: 25/7/2016

\section{RESUMEN}

El presente trabajo aborda el tema de la migración indígena en la península de Yucatán, México, a partir de los testimonios de sus protagonistas. Basado en el trabajo etnográfico realizado en comunidades mayas del estado de Campeche durante dos años, el texto propone un recorrido diacrónico por los diferentes procesos y variables migratorias que se han visto obligados a afrontar en las últimas cinco décadas los mayas peninsulares, tratando de escapar de la pobreza endémica que padecen en sus comunidades. Más allá del alejamiento de sus familias, hogares, comunidades y cotidianeidad cultural, los testimonios recabados entre los migrantes ilustras los mecanismos que emplean los mayas para, pese a la distancia y las dificultades que encuentran, mantener vivos los vínculos con sus comunidades de origen, y un fuerte sentido de pertenencia basado en la vigencia de ciertos símbolos sagrados.

Palabras clave: mayas peninsulares, migración, identidad, historias de vida, etnografía.

\section{Ethnographic Sketches on the Migration of Peninsular Mayans from Campeche}

\begin{abstract}
Using oral testimonies, this study analyses the migration of indigenous peoples from the state of Campeche, Mexico. Based on two years of ethnographic work carried out in the region, I propose a diachronic overview of the different migratory processes and variables that the migrants have had to confront in the last five year period, in their attempt to escape the endemic poverty that endures in their communities. Beyond leaving behind their families, homes, communities and cultural continuities, the testimonies I have compiled from the migrants illustrate the mechanisms the Mayan people use -despite tremendous obstacles and distances- to keep alive the crucial links to their place of origin, through a strong sense of belonging based on the permanence of certain sacred symbols.
\end{abstract}

Key words: peninsular Mayas, migration, identity, life stories, ethnography.

Sumario: 1. Introducción. 2. Los pioneros de la migración: la primera oleada migratoria hacia las capitales peninsulares. 3. Los rumbos actuales de la migración: la ciudad de Mérida y la Riviera Maya. 4. A modo de colofón: impactos de la migración en las comunidades indígenas. 5. Referencias bibliográficas

\section{Introducción}

Irse para regresar es una de las premisas que, antes o después, solían aparecer durante las conversaciones que mantuve con los vecinos de Nunkiní que experimentaron la migración en algún momento de sus vidas a lo largo de las últimas seis décadas. Efectivamente, los miembros de las casi 100 familias que he podido visitar en los últimos dos años (todas ellas con algún migrante entre sus miembros) aseguran que marcharse a trabajar «fuera» era sólo un mecanismo para obtener unos ingresos que en el pueblo se les niegan. Una mera estrategia de supervivencia que, combinada con otras, ha estado presente en la historia de los mayas peninsulares desde antes incluso de la llegada de los españoles. 
Así, por ejemplo, los movimientos demográficos de «gran envergadura» que provocaron las sucesivas oleadas migratorias protagonizadas por grupos toltecas y nahualizados, que arribaron a la península de Yucatán durante los periodos Clásico y Posclásico procedentes del Golfo y los altiplanos centrales, sojuzgaron y obligaron al reacomodo de los grupos nativos que se encontraban ya asentados en el territorio peninsular (Ruz 2009: 14-20) ${ }^{1}$. Durante la época colonial, la población indígena de la Península conoció diversos e intensos desplazamientos de población, motivados, en primera instancia, por los procesos de concentración o «reducción» forzosos a los que sometieron la Iglesia y la Corona a los habitantes de los antiguos asentamientos prehispánicos, buscando con ello establecer un rígido control sobre la población con fines militares y de evangelización (Bracamonte y Solís 1996: 68-69) ${ }^{2}$. También bajo el dominio hispano, Nancy Farriss ha mostrado como los mayas debieron recurrir a distintas formas de migración: bien para escapar del yugo impuesto por los nuevos señores en forma de tributos y trabajos forzados («huida» a la montaña), bien tratando de encontrar acomodo y tierras cultivables en otras poblaciones sujetas al régimen colonial, diferentes a las de origen («la deriva»), o creando nuevos «asentamientos satélites» en la periferia de los pueblos cabecera congregados (Farriss 2012: 270 y SS.) $)^{3}$.

Tras la independencia, y con la llegada del periodo liberal, los mayas no abandonaron esta añeja práctica de cambiar su lugar de residencia con el fin de asegurar su subsistencia o resistir a las ambiciosas pretensiones de las élites criollas, ahora ya orgullosamente nacionales. Efectivamente, desde los albores del siglo XIX, «en un sentido nunca antes experimentado, las comunidades iban perdiendo tanto gente como tierras en aras de [...] la hacienda» (Farriss 2012: 497), pues los dueños de las plantaciones henequeneras necesitaron cubrir la ingente mano de obra que requerían estos cultivos extensivos. A pesar de que una parte importante de la población maya peninsular acabó residiendo y trabajando en estas haciendas al no contar con otras alternativas de supervivencia, ante la ausencia de tierras comunales en sus comuni-

\footnotetext{
1 Estas sucesivas oleadas poblacionales produjeron, además de una profunda huella en el registro arqueológico de la Península, importantes marcas en textos coloniales como el Chilam Balam de Chumayel, en el que se dan las fechas precisas del descubrimiento, conquista, poblamiento y abandono de varias poblaciones por los extranjeros (Ruz 2009: 16). Asimismo, a fines del Clásico Tardío y en el Posclásico, en Chichen Itzá, se hace patente que las modas y los sistemas de creencias y de culto se vieron alterados por la más que probable presencia de gentes procedentes del centro de México (Lacadena y Ciudad 2009: 69-71).

2 Al respecto, Pedro Bracamonte y Gabriela Solís (1996) han señalado que el principal problema que enfrentaron los conquistadores ibéricos fue el de la dispersión de la población maya, lo que impedía establecer un control efectivo sobre ella y dificultaba «la conquista espiritual». Así, por ceñirme únicamente al área donde se llevó a cabo esta investigación, mencionar que, para 1565, los españoles habían concentrado en la actual Calkiní (capital de la provincia prehispánica de los Ah Canul) a los habitantes de nueve pueblos aledaños, entre los que se contaban Nunkiní y Halachó, siendo el primero reubicado en su antiguo emplazamiento a fines del siglo XVI (Okoshi 2009: XV; Quezada 1993: 124).

3 Además en la segunda mitad del siglo XVIII (1770) se dieron importantes movimientos demográficos entre la población nativa de la Península a raíz de la severa crisis agrícola desencadenada tras varios años de fenómenos atmosféricos adversos (sequias y huracanes) y plagas de langosta, que provocaron las consiguientes hambrunas. La migración, sobre todo hacia las fincas de españoles, se convirtió así en una estrategia de supervivencia para los mayas, que buscaron de esa forma escapar a la inanición y a las enfermedades asociadas al hambre, amén de evadir las exigencias tributarias que en épocas de calamidad se hacían más onerosas (Peniche 2009: 189-204).
} 
dades (mismas que habían sido adquiridas por los propios hacendados), no faltaron tampoco quienes optaron por huir hacia áreas remotas de la Península para continuar con sus formas tradicionales de vida ${ }^{4}$. Pero además de esta segunda congregación a la que se vieron forzados muchos mayas por la ambición de los hacendados y sus aliados políticos (ya no con fines evangelizadores, sino de explotación económica), el comienzo de la llamada Guerra de Castas en 1847 provocó también importantes y continuos movimientos migratorios por toda la Península: tanto los movimientos que protagonizaron quienes, para escapar de la esclavitud y los abusos de las autoridades políticas y religiosas, huyeron hacia las selvas del oriente para engrosar las filas de los sublevados, como los que, buscando la protección de las tropas yucatecas, marcharon en dirección poniente ante el miedo a los ataques y saqueos de los mayas rebeldes ${ }^{5}$.

Pero además de las señaladas, otra migración con carácter forzoso que en el siglo XIX fueron obligados a realizar miles de mayas, fue la que protagonizaron los que cayeron prisioneros durante los primeros años de la Guerra de Castas. Ésta fue, además, legalizada mediante un decreto del gobierno yucateco en 1848, y significó para los mencionados prisioneros su traslado y posterior venta como esclavos en Cuba, donde los latifundistas azucareros hispanos estaban ávidos de hallar mano de obra tras la reciente prohibición de traficar con esclavos procedentes del continente africano (Ruz 2009: 30).

En la actualidad, como viene sucediendo a lo largo de toda la historia, la migración se ha mantenido como una constante en la vida de los mayas peninsulares, los cuales se siguen viendo obligados a recurrir a ella principalmente por motivos de carácter económico. Efectivamente, la crisis del sistema tradicional de milpa, la falta y el agotamiento de las ya de por sí magras tierras ejidales, el hundimiento de la industria henequenera regional, la pobreza endémica que sufren las comunidades, las carencias y la precariedad en los servicios básicos de salud o educación que padecen, la falta de nuevas oportunidades laborales, e incluso el deseo de conocer y experimentar nuevas formas de pensar y vivir por parte de los más jóvenes, son algunos de los factores que influyen en la actualidad para que los mayas continúen abandonando sus comunidades rumbo a los centros urbanos y turísticos regionales para insertarse en el mercado laboral regional ${ }^{6}$. Así, los lugares de destino de estos migrantes suelen ser las ciudades más importantes de la Península, principalmente Mérida, Campeche o Cancún, sumándose en los últimos tiempos otros núcleos urbanos pertenecientes al

\footnotetext{
4 En épocas tempranas, los trabajadores de las haciendas que no estaban contentos con sus amos «procuraban separarse por medios lícitos -ir a donde mejor nos parezca, decían-, pidiendo sus ajustes de cuenta y comprometiéndose a pagar, aunque no tuvieran a favor ni a las autoridades ni a los amos» (Machuca 2010: 84). Con el gobierno del general Lázaro Cárdenas, las tierras que habían acaparado los hacendados regresaron a las comunidades en forma de ejidos, consiguiendo que los antiguos peones volvieran a sus poblaciones.

5 La brutalidad de la explotación sufrida en las haciendas fue una de las causas del estallido de la Guerra de Castas, provocando además que muchos mayas abandonaras sus comunidades de origen y fundaran en las selvas del actual Quinta Roo la que sería la capital del territorio cruz'oob que abarcaba hasta Belice, donde llegaron a vivir dispersos entre 35 y 40.000 personas (Ruz 2009: 34).

6 Trabajos como los de Mario Humberto Ruz (2007 y 2009), Jesús Lizama (2007), Magalí Daltabuit (2009), Luis Alfonso Ramírez (2002) o Pedro Lewin (2008), entre otros, profundizan en las diferentes y complejas causas que están detrás de los procesos migratorios contemporáneos que protagoniza la población indígena peninsular.
} 
corredor turístico de la denominada Riviera Maya, como Playa del Carmen o Tulum ${ }^{7}$. Dada la escasa o nula formación que tienen en su gran mayoría, en las ciudades los migrantes indígenas se desempeñan en los empleos menos cualificados y peor remunerados, tales como peones de albañil, jardineros, mozos de almacén y, en el caso de las mujeres, en el servicio doméstico o del cuidado de los niños, o bien como camareros, botones, «seguridad» o mucamas cuando de laborar en los grandes complejos turísticos del Caribe se trata.

Tras haber presentado hasta aquí un somero bosquejo diacrónico de la migración indígena de la Península, mi intención ahora es descender y enfocar la mirada hacia algunas comunidades del municipio de Calkiní, ubicado en la región cultural del Camino Real de Campeche ${ }^{8}$. Pretendo con ello ofrecer un panorama más detallado, de corte etnográfico, sobre el fenómeno migratorio que ha vivido esta región, a partir de las experiencias que me fueron narradas por sus protagonistas. A partir de ellas será posible recrear las condiciones de pobreza endémica que empujaron a los mayas a salir de sus ámbitos locales de confort, siempre con la aspiración de sostener a sus familias y dar a sus descendientes las oportunidades que ellos nunca disfrutaron. Trataré de ilustrar, a su vez, la forma en que tanto los destinos como los tiempos y formas que adoptaron los desplazamientos en busca de empleos asalariados se han venido modificando notablemente con el paso de los años, aunque la necesidad de recurrir a la migración como estrategia de supervivencia se ha mantenido como una constante en la cotidianeidad de las familias indígenas en las últimas seis décadas.

Asimismo, con vistas a dotar de un carácter diacrónico a la mirada que ofreceré sobre el fenómeno migratorio, recurriré a relatos ofrecidos por migrantes pertenecientes a diferentes grupos de edad. Comenzando por quienes fueron los pioneros en dejar sus comunidades con rumbo a las ciudades allá por los años cincuenta del siglo pasado, hasta llegar a los jóvenes que en la actualidad continúan marchándose, en algunos casos contando ya con preparación universitaria. Basándonos en estas realidades contrastantes podremos vislumbrar el panorama de las cambiantes y heterogéneas características que ha venido adoptando la migración laboral a lo largo de las últimas décadas en las comunidades indígenas donde se realizó el trabajo de campo.

Por último, amén de abordar los aspectos característicos de la migración (destinos, durabilidad, motivaciones, etc.), recurriendo a los testimonios ofrecidos por mis in-

\footnotetext{
7 Aunque, a diferencia de otras partes de la República, la migración de los mayas ha sido predominantemente regional por la continua demanda de mano de obra que ha ejercido el polo turístico de la Riviera Maya. A partir de los años 80, y sobre todo en los 90, vecinos de varios municipios del centro y sur de Yucatán como Oxkutzcab, Muna, Peto, Cenotillo o Tunkas comenzaron a migrar hacia los Estados Unidos atraídos por mejores salarios (Lewin 2008: 40-42). Actualmente, cálculos conservadores hablan de 50.000 migrantes yucatecos sólo en el estado de California (Ruz 2009: 43).

8 Varios autores han propuesto subdivisiones del espacio peninsular en regiones o área culturales (Quintal et al. 2003; Ruz 2002a). Éstas obedecen a diversas características geográficas, económicas, sociopolíticas y culturales, así como a los divergentes procesos históricos que ha vivido la Península en su conjunto, lo que ha dado como fruto una cierta regionalización (Ruz 2006). Según Quintal et al. (2003: 300), la población que habita la microrregión del Camino Real se caracteriza por tener en la agricultura de milpa, la horticultura, la producción de artesanías y el trabajo migratorio sus principales «estrategias de vida», amén de «conservar un elevado porcentaje de hablantes de lengua maya [...], y un apego especial a sus rituales y ceremonias «ancestrales».
} 
terlocutores buscaré rescatar las percepciones que éstos me ofrecieron relativas a sus nuevos espacios de trabajo y sus propias comunidades de origen, referentes obligados en la comparación con los primeros. Así, como un juego de espejos contrapuestos, son una gran mayoría quienes tienden a revalorizar su propia matriz cultural étnica cuanto más distantes se hallan de sus poblaciones de origen. Lo anterior se entrevé, por ejemplo, en la opción por la que optan, tarde o temprano, buena parte de los migrantes: retornar a sus lugares de origen, junto a sus familias, en cuanto ello les resulta posible, bien los fines de semana o cuando su edad les impide viajar y realizar trabajos físicos. En el caso de los que migraron y se quedaron a residir definitivamente en las ciudades donde encontraron trabajo llevándose a sus familias, lo más habitual es que mantuvieran (o construyeran) una residencia en el pueblo a la que regresar tras la jubilación, amén de no dejar pasar la ocasión de regresar a él cada vez que se acercaba la conmemoración de algún evento de especial trascendencia en el calendario festivo local o familiar, como puede ser la fiesta del santo patrón de la población (novenario), las celebraciones de difuntos en el mes de noviembre (janal pixán) o alguna ceremonia de carácter agrícola como el janlikool. Con estos retornos temporales o definitivos, los migrantes reafirman sus lazos de pertenencia a la comunidad donde nacieron y se criaron, mostrando además que ésta sigue siendo un punto de referencia esencial al momento de trazar sus identidades.

Otro aspecto que aparece de manera constante y consistente en los testimonios recopilados en las comunidades de Calkiní remite al lado más oscuro de la migración indígena. Se trata de aquel que muestra el racismo explícito que aún persiste en la sociedad hegemónica regional hacia la población originaria de la Península, el cual se deja entrever, entre otros aspectos, en los ínfimos salarios que perciben y en las precarias condiciones laborales que padecen la gran mayoría de los migrantes mayas (carentes de seguro médico, trabajando a destajo y de manera informal, por citar solo algunas) ${ }^{9}$. No debe extrañarnos, por tanto, que en base a las prolongadas jornadas laborales que acometen y las bajas retribuciones que perciben por ellas, en no pocas ocasiones reviva en la ancestral memoria indígena los pretéritos tiempos de la esclavitud como una suerte de pervivencia en el presente.

\section{Los pioneros de la migración: la primera oleada migratoria hacia las capitales peninsulares}

En el presente epígrafe me concentraré en las experiencias que me fueron narradas por los ancianos. Aquellos que siendo jóvenes, a mediados del siglo pasado, se vieron obligados a salir de sus pueblos y abandonar a sus familias para buscar trabajo en la ciudad. Más allá del hecho común de compartir esta experiencia vital, las motivacio-

\footnotetext{
9 Esta situación de franca desventaja en la que se insertan en el mercado laboral regional los mayas peninsulares deriva, como ha señalado Jesús Lizama (2007: 10-11), «de las conformaciones históricas que han propiciado que su integración a los procesos de orden mundial se produzca en una situación de desventaja o subordinación con respecto a otros grupos o sociedades». Lo anterior provoca, que participen de manera ínfima en la redistribución de una riqueza de la que ellos mismos, con su trabajo diario, son los principales generadores (Lizama 2007: 128).
} 
nes, expectativas y visiones en torno a sus lugares de origen y destino que subyacen en los testimonios de mis interlocutores resultan coincidentes, producto de su pertenencia a una matriz cultural maya de corte «tradicional» que, a diferencia de la heterogeneidad que ofrecen las comunidades en la actualidad, adoptaba características bastante homogéneas y se materializaba en torno a una serie de rasgos culturales bien definidos. Entre éstos se cuentan un fuerte sentimiento de apego hacia la comunidad de origen, el predominio del trabajo agrícola basado en el cultivo de milpa de temporal, una gastronomía cuya base la constituían los productos obtenidos en ella y en el solar doméstico, el uso cotidiano y generalizado de la lengua maya, determinadas formas de organización social y laboral (con base en la familia extensa), y la plena vigencia de un sistema cosmológico particular, entre otros. Estos rasgos eran compartidos y asumidos como propios por la gran mayoría de los indígenas peninsulares, y no eran abandonados cuando de salir a trabajar fuera se trataba. La fortaleza de este conjunto de prácticas y creencias permitió que, a pesar de las décadas que los migrantes pasaron yendo y viniendo entre sus comunidades y las urbes peninsulares, cuando éstos optaron por reasentarse definitivamente en sus poblaciones de origen conservaran, reivindicándolos, muchos de aquellos rasgos en torno a los cuales construyen una parte importante de sus propias identidades de carácter étnico y local ${ }^{10}$.

Situarse y revivir la cuarta y quinta década del siglo pasado a través de los testimonios recopilados en diversas poblaciones del municipio de Calkiní supone hacerlo en lo que los ancianos denominan «el tiempo de la esclavitud». A pesar de los años transcurridos, no deja de impresionar al etnógrafo la profusión de detalles con que, aún hoy, los informantes rememoran las penosas condiciones de vida y de trabajo que, desde los 13 o 14 años, afrontaban en los ranchos henequeneros, propiedad siempre de familias con apellidos hispanos. Una situación que se veía agravada, además, por la total ausencia de servicios básicos que padecían en sus comunidades, donde no sólo no existían carreteras, escuelas (la única primaria de Nunkiní, por ejemplo, funcionaba en una casa) o servicios de salud pública, sino que la luz y el agua «brillaban» por su ausencia. Todo lo anterior se conjugaba para conformar un panorama desolador y sin expectativa de mejora para los más jóvenes. Éstos percibían la mera supervivencia de sus familias recién formadas como una odisea sin garantía de éxito, en la que migrar hacia alguna de las capitales de los estados peninsulares se comenzó a vislumbrar como una opción ineludible, aunque indeseada en la mayoría de los casos.

Muchos son los que rememoran como desde niños debían afrontar extenuantes jornadas de trabajo en alguna de las fincas henequeneras que, como San José, San Joaquín o Santa Cruz, rodeaban sus poblaciones, para de esa forma poder contribuir con ingresos a las precarias economías campesinas de sus familias. Jornadas de doce

10 No es mi intención aquí identificar automáticamente o describir a una cultura como la maya en base a un mero listado de rasgos culturales «esenciales» como los aquí enumerados; más bien destaco que, para mis interlocutores, el hecho de hablar maya cotidianamente, sembrar la milpa y consumir sus productos, o la creencia en un universo habitado al unísono por santos católicos y toda una pléyade de «dueños» de la naturaleza (Yumtzilo'ob), entre otros rasgos, les permiten autoadscribirse a una colectividad particular de carácter étnico (nosotros) y, al mismo tiempo, diferenciarse por confrontación del resto de la sociedad regional (los ts'uulo'ob) con cuyos integrantes no comparte tales rasgos (los otros) (Bartolomé 2006: 46). 
horas que daban comienzo a las cuatro de la mañana, cuando los atronadores silbatos de las casas de máquinas interrumpían el sueño de todos los habitantes de los pueblos (fueran o no sus trabajadores). Estas jornadas, en el mejor de los casos, se veían retribuidas con salarios de tres pesos y medio por día; y eso cuando los trabajadores no eran obligados a pasar por la tienda de raya para recibir allí sus jornales en especias, en forma de maíz, frijol, pan o chocolate. En aquellos tiempos, trabajar en los plantíos constituía la única forma de obtener ingresos en metálico con los que poder adquirir aquellos productos que no producían las milpas o solares familiares, e insumos de uso cotidiano, como ropa, jabón o herramientas para las faenas agrícolas.

Por su parte, las milpas donde se cultivaban los productos básicos de la dieta familiar (tales como el maíz, frijol, chile o calabazas) se ubicaban en los terrenos más depauperados, improductivos y pedregosos, pues los de mayor calidad habían sido acaparados por los ranchos henequeneros desde el siglo XIX. Ello provocaba que, a duras penas y con mucho esfuerzo, lograran proveer, cuando la temporada de lluvias había sido propicia, lo suficiente para cubrir el abastecimiento familiar durante el año. Cuando las lluvias se retrasaban o eran insuficientes la situación de carestía en los pueblos se volvía dramática, y el hambre empujaba a varones de todas las edades a emplearse en las fincas henequeneras a cambio de escuetas raciones de comida. «Nos dolía mucho el hambre», afirmaban dramáticamente don Antonio Huchín y Fernando Chi, antiguos migrantes de 82 y 78 años respectivamente, al recordar aquellos tiempos; cuando un huevo duro cortado con un hilo en cinco partes daba de desayunar a otros tantos hermanos, o tres tortillas de maíz untadas en un chile max constituían el único alimento que ingerían los miembros de una familia campesina antes de irse a dormir. Aunado a las cíclicas carestías que padecían, las características que destacan del trabajo agrícola quienes lo practicaban, bien en las milpas o en los plantíos de henequén, eran su gran «dureza» y los nulos beneficios que, más allá de la mera subsistencia familiar, les proporcionaba.

Así, buscando mejorar estas duras condiciones de vida, y con la vista puesta en tratar de ofrecer a sus hijos la oportunidad de estudiar para salir de la pobreza que ellos habían conocido, tras consensuar la decisión final con el cabeza de familia del grupo familiar extenso, muchos de los jóvenes varones que con 18 o 19 años contraían matrimonio y veían nacer a sus primeros vástagos comenzaron a optar por abandonar sus comunidades de origen con rumbo a alguno de los centros urbanos peninsulares más cercanos, preferentemente Mérida o Campeche. A la hora de decantarse por uno de éstos se daba prioridad a aquel en el que el migrante contara con alguna red de apoyo, conformada por algunos familiares o «paisanos» del mismo pueblo que estuvieran ya residiendo y trabajando allí, los cuales pudieran brindarle apoyo a su llegada para cubrir sus necesidades básicas de hospedaje y alimentación, así como ayudarle en la búsqueda del primer empleo.

Repasando los discursos de los protagonistas de esta primera oleada migratoria, destaca por encima de todo su deseo de ganar dinero para poder enviarlo a sus familiares en el pueblo y colaborar así en su manutención. En ningún caso escuché alusiones a deseos de enriquecimiento personal como una de las motivaciones para migrar (algo más habitual entre los jóvenes en nuestros días). Y es que en aquellos tiempos (y en menor medida en la actualidad) las familias extensas mayas funcionaban como 
verdaderas unidades solidarias y redistributivas, pues en ausencia de sus maridos, esposas e hijos quedaban bajo la responsabilidad de sus suegros y cuñados, quienes residían en el mismo hogar o solar familiar ${ }^{11}$. De esa forma se evitaba el desamparo de las mujeres y los niños en ausencia de sus esposos y progenitores migrantes, lo que sin embargo provocaba en ciertas ocasiones episodios de abusos y enfrentamientos entre suegras y nueras. Asimismo, cuando el varón ausente comenzaba a trabajar y podía enviar o llevar dinero a la comunidad, éste era recibido por su padre (bien en mano, bien en el puesto de telégrafos de la cabecera municipal), quien lo redistribuía de acuerdo con las necesidades básicas de los integrantes del grupo doméstico. Hecho esto, y cuando ello era posible, el jefe de familia entregaba una parte del dinero a la esposa de su hijo migrante, para que ella se encargara de ahorrarlo con la mente puesta en la futura construcción de una vivienda propia, siempre dentro del solar familiar. Así, aunque ausentes, el plan de vida de los jóvenes migrantes consistía, en primera instancia, en poder construir una vivienda propia en sus comunidades de origen para que la habitaran su esposa e hijos (y ellos mismos los días en que regresaban de la ciudad o tras su jubilación). Esta prioridad, presente en los relatos de todos los migrantes, nos remite a sus deseos de no abandonar irreversiblemente sus comunidades y de retornar a ellas de manera definitiva en cuanto les fuera posible hacerlo.

En las ciudades, los empleos exiguamente retribuidos y poco o nada cualificados que desempeñaron los primeros jóvenes que salieron de sus comunidades no han variado demasiado respecto a los que siguen ocupando hoy en día la mayoría de los mayas que cada lunes salen «a buscar suerte» en las ciudades ${ }^{12}$. Ante la ausencia en sus comunidades de escuelas que impartieran más allá de la primaria (la única opción para estudiar secundaria era desplazarse diariamente hasta la cabecera municipal con los gastos que ello conllevaba) y la necesidad de abandonar prematuramente sus estudios para poner a disposición de las precarias economías familiares su fuerza de trabajo, los mayas que partían hacia las ciudades adolecían de cualquier preparación especializada, estando en el mejor de los casos cualificados para leer, escribir y realizar cuentas matemáticas básicas.

En tales circunstancias, y aprovechándose de las apremiantes necesidades que tenían los migrantes por enviar dinero a sus familias, la calidad de los trabajos que les ofrecían en las ciudades dejaban mucho que desear, tanto por los bajos salarios que percibían como por la precariedad a la que estaban sujetos. A pesar de todo, los informantes señalan que como peones de albañilería, pintores, porteadores, jardineros, veladores o conserjes, podían ver aumentar hasta en un mil por ciento sus ingresos

11 Entre los mayas peninsulares ha predominado, y predomina hasta nuestros días, un patrón de residencia postmarital de carácter patrilocal, al menos durante los primeros años de matrimonio. Sólo cuando la familia del varón carece del espacio y los recursos para dar cabida a la nueva pareja, ésta fija su residencia con los padres de la mujer.

12 En la actualidad observamos que en las comunidades del Camino Real predomina la migración de carácter pendular. Así, cada lunes salen de sus pueblos cientos de hombres y mujeres con destino a las ciudades de Mérida y Campeche, donde se emplean en su mayoría como peones de albañilería y en el servicio doméstico respectivamente. Después de permanecen toda la semana en sus lugares de trabajo, regresan a sus hogares los sábados en la tarde. Este patrón se repite también en muchas comunidades mayas de los estados de Yucatán y Quintana Roo, donde a los destinos laborales de los migrantes ya referidos se añaden los centros urbanos del turístico Caribe mexicano (Cárdenas 2013: 165 y ss.; Lizama 2007: 115-116) 
respecto al miserable jornal que percibían por trabajar en los planteles de henequén. Gracias a estos ingresos consiguieron atenuar rápidamente la precaria situación en la que vivían sus familias en las comunidades, lograron levantar sus propias casas de material y, con el tiempo, hicieron por sus hijos lo que sus padres nunca pudieron hacer por ellos: darles estudios profesionales con los que poder escapar de la pobreza endémica que padecían las comunidades. Con ello reconocían de manera implícita que las «tradicionales» tareas agrícolas no tenían ya futuro y sólo auguraba más miseria para sus descendientes. Eso sí, únicamente los varones eran los destinatarios de este privilegio, pues las mujeres, como apuntaba don Fernando en Nunkiní, «se casaban pronto y marchaban con sus maridos, así. Entonces ya no servía para nada el estudio»!.

Pese a las evidentes mejoras que lograron en los niveles de vida de sus familias, los protagonistas de esta primera migración no dejan de evocar los sentimientos de necesidad que les impulsaron a marcharse (siempre en contra de su voluntad), dejando atrás tanto a sus padres, esposas e hijos pequeños, como la vida en la comunidad y el trabajo en el campo, que les había sido inculcado desde la infancia por sus padres. Por eso cuentan, no sin cierto punto de orgullo, que cada vez que tenían la oportunidad regresaban a sus comunidades, aunque fuera uno o dos días, para visitar y convivir con sus familiares y amigos, trabajar en la construcción de sus casas e ir a la milpa para colaborar con sus padres y hermanos en la siembra, chapeo o cosecha. Hasta la fecha reconocen que durante esas breves jornadas en las que volvían a sus pueblos y se desempeñaban en tareas que consideran como propias de su condición étnica y campesina, es cuando se encontraban realmente felices y «tranquilos». Compensaban y dotaban de sentido así al esfuerzo cotidiano que suponía para ellos tener que vivir alejados del territorio y del ambiente que sentían como propio, al tiempo que reafirmaban su profundo sentido de pertenencia hacia su comunidad, en contraposición a la radical «otredad» a la que, por necesidad, se veían obligados a regresar y con la que tenían que convivir cotidianamente a su regreso a la ciudad.

Una clara muestra de la fortaleza de los nexos de pertenencia y autoadscripción que mantenían los migrantes con sus comunidades la hallamos en el hecho de que, ni la distancia ni las prolongadas ausencias implicaban el olvido o desatención de sus obligaciones religiosas, contraídas en tanto que miembros de facto de sus poblaciones de origen. Así, por mencionar un ejemplo, la devoción hacia quienes constituyen los principales símbolos sagrados locales, personificados en la figura de los respectivos santos patrones ${ }^{13}$, implicaba cada año el puntual retorno de muchos migrantes para poder asistir a las celebraciones en honor del santo de su comunidad (novenario), así como en su activa participación en las distintas actividades, sagradas y profanas que daban, y todavía hoy dan, forma a los sistemas festivos con que los mayas peninsulares honran a los mecenas sagrados de sus poblaciones. Las fiestas patronales conformaban y conforman tiempos y espacios en los que los vecinos de las comunidades

13 Bajo esta característica, los santos patrones vendrían a cumplir con las funciones que enunciara Clifford Geertz (2005: 87-92) sobre los símbolos de naturaleza sagrada, a saber: que tienen la cualidad de sintetizar el ethos de un pueblo, su estilo estético y moral, su calidad de vida, su carácter y su cosmovisión; al tiempo que forman parte de un proceso en continua producción, utilización y transformación de la práctica colectiva de producción simbólica. 
reafirman sus identidades colectivas y territoriales, al tiempo que refuerzan los lazos de solidaridad y reciprocidad al interior de las poblaciones (Lizama 2007; Quintal et al. 2003; Ruz 2007) ${ }^{14}$. Por ello, hasta el presente se vuelven momentos propicios para que quienes pasan la mayor parte del año laborando fuera de ellas puedan mostrar públicamente la vigencia y fortaleza de sus sentimientos de pertenencia hacia la colectividad, simbolizada en la figura del santo patrón correspondiente, mediante su inserción en alguna de las sociedades de devotos encargadas de solemnizar los festejos religiosos (gremios) o asumiendo la construcción de alguno de los palcos que conforman el ruedo en el que se desarrollan las corridas de toros durante la Feria. Por su parte, cuando un migrante no podía o no puede regresar para la fiesta se encarga de enviar puntualmente una importante suma de dinero a su familiares, para que éstos puedan tomar parte activa en los festejos, amén de costear rezos ante el altar doméstico $u$ ofrendar en nombre del familiar ausente un animal a alguno de los gremios que desfilarán durante las jornadas de fiesta.

El deseo de los migrantes por retornar a sus comunidades de origen y restablecerse en ellas de forma definitiva se podía cumplir una vez que sus hijos varones lograban finalizar sus estudios magisteriales en alguna de las dos escuelas Normales que existían en la región del Camino Real campechano. Así, tras dos o tres décadas de ausencia pero con los objetivos originarios de su marcha cumplidos, la mayoría de estos hombres regresaron para reintegrarse a la vida cotidiana de sus poblaciones, retomando aquellos roles sociales y cosmológicos que en su condición de jefes de familia les correspondían; tanto en lo que tocaba al trabajo en el campo, con la cría de ganado y la siembra de milpa, como en el ámbito de las prácticas propias de la religiosidad local ${ }^{15}$. Esto último implicaba, por ejemplo, continuar velando por el correcto y puntual cumplimiento de los diversos rituales y ofrendas que cada año deben entregar en su nombre los especialistas rituales locales (jmeeno' $o b$ ), en milpas y solares, a las añejas deidades mayas de la foresta, las milpas, los aires y la lluvia, quienes son consideradas los «dueños originarios» de los espacios naturales, habitacionales y productivos. De su regular realización dependen, en buena medida, el éxito de futuras cosechas y la cría de animales domésticos, la productividad de los apiarios y, en última instancia, la salud de los seres humanos ${ }^{16}$. En definitiva: el bienestar holístico del núcleo familiar.

14 Sobre el importante papel que juega el culto a los santos patrones en las poblaciones nativas de Mesoamérica, Bartolomé ha señalado que son fundamentales para construir «una comunidad ritual colocada bajo la advocación de una divinidad tutelar» (2006: 104).

15 En la actualidad, la religiosidad de los mayas peninsulares, como la de buena parte de los pueblos nativos del área cultural mesoamericana, está conformada por un conjunto de entidades, prácticas y creencias originarias de dos universos culturales radicalmente diferentes: el amerindio y el catolicismo importado por los conquistadores ibéricos en el siglo XVI. Durante los últimos cinco siglos esta conjunción dio lugar a un sinfín de reconfiguraciones que «supusieron procesos de sincresis, apropiación, resimbolización y refuncionalización de la religión impuesta para lograr hacerla propia al compatibilizarla con los códigos preexistentes», por parte de las sociedades originarias (Bartolomé 2006: 103).

16 Buena parte de las entidades sagradas de raigambre maya, denominadas genéricamente «dueños» (Yumtzilo'ob), moran y se vinculan directamente con a los ámbitos productivo, doméstico y natural. Poseen éstas una gran relevancia en el binomio salud-enfermedad, en tanto que son la causa de un buen número de padecimientos derivados tanto de su propia naturaleza poderosa o de castigos hacia quienes descuidan sus 
Peor suerte que los hombres corrieron las mujeres, quienes se veían obligadas a abandonar sus comunidades de origen y a sus familias antes de alcanzar la mayoría de edad. En estos casos, eran sus propios progenitores los que, ante la imposibilidad de poder sacar adelante a todos sus hijos, optaban por entregar a sus hijas a matrimonios que se marchaban para ocupar sus recién obtenidas plazas de maestros con el fin de que les sirvieran de nanas y quedaran al cuidado de sus hijos mientras salían a trabajar. A cambio del trabajo de sus hijas, los padres recibían una pequeña compensación económica mensual, amén de liberarse «de una boca más que alimentar», lo que permitía aumentar ligeramente las raciones de alimentos destinadas a los que permanecían en el hogar. Según los testimonios recopilados al respecto, las condiciones en las que vivían y trabajaban estas niñas eran, en muchos casos, difíciles y abusivas, pues, además de estar alejadas de cualquier soporte afectivo y del contacto con sus familiares, sus patronas las obligaban a hacerse cargo de tareas que originalmente no les correspondía, tales como la limpieza del hogar, cocinar o el cuidado del jardín, a las cuales se sumaba el ya pactado cuidado de los niños. Lo anterior acarreaba a las niñas extenuantes jornadas de trabajo, no siempre correspondidas con raciones de comida apropiadas. No es de extrañar que, tras un par de experiencias de este tipo, muchas de estas jóvenes, cuando regresaban a sus comunidades con motivo de algún periodo festivo, lloraran amargamente ante la presencia de sus padres para evitar volver a ser enviadas de regreso con sus «familias adoptivas». O que en cuanto cumplían los 16 años buscaran contraer matrimonio con algún joven de la misma población, con vistas a evitar tener que repetir la experiencia de salir de la comunidad en las condiciones ya referidas.

\section{Los rumbos actuales de la migración: la ciudad de Mérida y la Riviera Maya}

A pesar del tiempo transcurrido de esta que he considerado, al menos desde el punto de vista de la memoria oral, «la primera oleada migratoria», sus consecuencias resultan hoy muy visibles y notorias en las comunidades que conforman el municipio de Calkiní. Gracias al esfuerzo de muchos de aquellos jóvenes que emigraron a las ciudades hace ya cinco décadas, alejándose en contra de su voluntad de todo aquello que constituía su mundo conocido y su núcleo afectivo, sus descendientes tuvieron la oportunidad de acceder a las escuelas magisteriales y hacer carrera como maestros de primaria y secundaria dentro del sistema de educación pública mexicano. Se aseguraron de ese modo unos ingresos quincenales fijos que garantizaban, como nunca antes en la historia local, la supervivencia de sus familias y, aún más, permitieron a sus propios hijos (nietos de nuestros anteriores protagonistas) tener la posibilidad de acceder a estudios universitarios. Así, en tan solo tres generaciones, las familias de aquellos pioneros que se marcharon a Mérida o a Campeche en busca de un mejor porvenir para los suyos, pasaron de vivir en una época que aún hoy se identifica con la «esclavitud», el hambre y la falta de futuro, a contar entre sus miembros con

obligaciones rituales o quebrantan determinados preceptos éticos o morales tenidos por «tradicionales»; se erigen de esta forma en guardianes del orden social de las comunidades (Ruz 2002b: 336). 
jóvenes licenciados que ya se comienzan a desempeñar, en alguna de las capitales y en otros centros urbanos, como profesionales en hospitales, laboratorios, oficinas, plataformas petroleras e instituciones gubernamentales.

Sin embargo, no todos los mayas que en la actualidad abandonan sus comunidades en busca de trabajo lo hacen en estas condiciones. Al contrario, como sucedía hace varias décadas, la gran mayoría de los migrantes que cotidianamente se ven en la obligación de marcharse en busca de una vida mejor para ellos y sus familias lo siguen haciendo sin haber podido concluir ni tan siquiera la educación básica obligatoria, lo que les relega a convertirse en mano de obra no cualificada, y restringe sus posibilidades en el mercado laboral a los empleos peor pagados y con mayores índices de precariedad. Así, las comunidades indígenas siguen conformando una fuente casi inagotable de mano de obra barata para los empresarios regionales e internacionales, quienes se aprovechan de la laxa legislación sobre derechos laborales que existe en México (como lo ejemplifica el hecho de que el salario mínimo legalmente aceptado sea de cuatro dólares por jornada de trabajo) para aumentar la producción de sus empresas y sus riquezas personales, a costa de pagar sueldos que, en el mejor de los casos, equivalen a setenta dólares por semana de seis días trabajados.

Sin embargo, algo que ha cambiado notoriamente con respecto a lo que veíamos en el epígrafe anterior es el aumento que ha experimentado la oferta de destinos a los que se dirigen en la actualidad los migrantes, aunque en la mayoría de los casos, en las poblaciones de Calkiní estudiadas, sigue predominando una migración de carácter «pendular-semanal» (Lizama 2007: 120) hacia las zonas urbanas, en la que los migrantes abandonan sus poblaciones los lunes de madrugada y retornan a ellas los sábados en la tarde ${ }^{17}$. Si bien como vimos la migración hacia las ciudades no es un fenómeno novedoso, lo que sí ha variado notablemente es el elevado número de personas que la practican y dependen de ella. También de carácter pendular, pero diaria, es la migración que tiene como destino alguna de las dos grandes maquiladoras textiles que funcionan en el área del Camino Real en su vertiente campechana, en las capitales epónimas de los municipios de Tenabo y Calkiní. Al respecto, la mayoría de los migrantes que salen de las comunidades trabajadas lo hacen para emplearse, de lunes a viernes, en la que se ubicada a las afueras de la población de Calkiní, capital del municipio al que pertenecen ${ }^{18}$.

\footnotetext{
17 Como han mostrado diversos autores que han estudiado en profundidad este fenómeno, se trata quizá de la variedad de migración más común en el ámbito indígena peninsular, seguido de otra de carácter permanente hacia los polos de desarrollo turístico en el Caribe mexicano (Cancún, Playa del Carmen o Tulum). La migración internacional hacia los Estados Unidos, tan importante en otras áreas de México, no es tan habitual entre los mayas peninsulares, con excepción de varías comunidades ubicadas en área central del estado de Yucatán que desde los años 90 se «especializaron» en este tipo de migración, hasta el punto que Pedro Lewin (2008: 27) apunta que «ilustran la emergente migración indígena hacia los Estados Unidos».

18 Las maquiladoras o «maquilas» son fábricas textiles de capital extranjero que se encargan de fabricar a bajos costes prendas de ropa para las grandes marcas norteamericanas del ramo, mismas que una vez hechas regresan al vecino del norte sin pagar aranceles para su posterior comercialización por todo el mundo. Los bajos salarios (no exceden de los 100 dólares por semana de trabajo), el trabajo monótono, los prolongados y estrictos horarios de 12 horas, las trabas para conformar asociaciones de trabajadores que puedan exigir ante los dueños mejoras laborales y la precariedad, son sólo algunas de las características que destacan quienes se emplean en las maquilas.
} 
Pero además de estas dos variedades de migración pendular hacia lugares más o menos cercanos que permiten a sus protagonistas regresar a diario o semanalmente a sus comunidades, a finales de la década de los setenta comenzaron a despuntar una nueva variedad de desplazamientos de carácter laboral hacia destinos mucho más lejanos, ubicados en diferentes puntos de la costa caribeña de la península de Yucatán, lo que obligó a los migrantes a prolongar sus periodos de ausencia de sus comunidades ${ }^{19}$. Así, fueron muchos los hombres mayas que se marcharon a trabajar como albañiles, primero a Cancún y una década más tarde a otros centros turísticos del Caribe mexicano como Playa del Carmen, Cozumel y Tulum ${ }^{20}$. Fueron ellos y otros mayas quienes, con su fuerza de trabajo, construyeron las carreteras y levantaron los centenares de hoteles, restaurantes y centros comerciales que cada año visitan cientos de miles de turistas europeos y norteamericanos, convirtiendo la actividad turística de esta zona en la tercera fuente de ingresos de la economía mexicana (Sierra y Campos 2013: 183), tras el petróleo y las remesas que envían los millones de mexicanos que viven y trabajan en Estados Unidos ${ }^{21}$. Debido a la distancia existente entre estos nuevos espacios laborales y las comunidades de origen de los migrantes, los elevados costes de transporte y a la permanente demanda laboral que se registra en estos lugares, muchos de los pioneros en salir de las poblaciones del municipio de Calkiní hacia el Caribe en los ochenta optaron por quedarse a vivir definitivamente en la periferia de alguna de las ciudades turísticas del Caribe, llevándose consigo a sus esposas e hijos $^{22}$. Muchos de ellos aseguraron haber visto aumentar sus niveles de vida y los de sus familias respecto a los que tenían cuando salieron de sus comunidades de origen, mejorando con ello sus posibilidades de acceso a servicios de salud y educación, y, una vez más, dando la oportunidad a sus hijos de acceder y concluir estudios superiores en alguna de las universidades locales. A pesar de ello, son muchos los que admiten que extrañan «la tranquilidad» de la vida que llevaban en sus pueblos y no descartan retornar a ellos una vez se hayan jubilado.

En la actualidad este flujo hacia el Caribe no ha cesado y resulta habitual que las familias cuenten con al menos uno de sus miembros radicando en algún punto de la Riviera Maya. La distancia y su ausencia no implican, sin embargo, que los migrantes

19 En la década de los setenta vio la luz un proyecto gubernamental apoyado por los organismos financieros internacionales para la construcción del que sigue siendo el principal desarrollo turístico de México y uno de los más importantes del mundo: Cancún (Daltabuit 2009: 275), ejemplo del turismo de masas de sol y playa, «representativo del uso desequilibrado de los recursos naturales» (Sierra 2009: 290).

20 Tras el éxito del proyecto Cancún, a finales del siglo XX siguió «el proyecto de desarrollo de la Riviera Maya» que se extiende por toda la costa Caribe del estado de Quintana Roo; muestra del desarrollo alcanzado por esta región turística lo tenemos en el hecho de que sus dos puntos más representativos, Playa del Carmen y Tulum, son dos de las ciudades con mayor crecimiento demográfico del continente americano (Cárdenas 2013: 161).

21 Lamentablemente, esta enorme contribución de los mayas peninsulares procedentes de todo el territorio peninsular a la generación de la riqueza nacional no se ha visto retribuida de manera equitativa en sus comunidades de origen, las cuales continúan copando los niveles más altos de marginalidad y pobreza a nivel regional en las encuestas (Ruz 2002a).

22 Entre 1976 y 1978 comenzó la construcción de hoteles a gran escala, lo que dio lugar a la primera gran oleada migratoria, integrada en casi un $90 \%$ por mayas peninsulares que se emplearon en la albañilería y se asentaron permanentemente en barrios (conocidos como «regiones») completamente segregados de la zona turística (Daltabuit 2009: 282), muchos de los cuales carecían (y aún carecen) de los servicios más básicos de habitabilidad (electricidad, agua, transporte, etc.). 
renieguen de sus comunidades de origen y olviden a quienes se quedaron residiendo en ellas. Por el contrario, las identidades territoriales se mantienen y se dejan sentir durante las visitas periódicas que realizan a sus familiares, coincidiendo con alguna celebración del calendario festivo local, y con el mantenimiento de la lengua maya como vehículo de comunicación familiar. Incluso en sus lugares de residencia y trabajo habitual los migrantes mantienen ciertas prácticas que los conectan con sus raíces. Es el caso del culto que dedican a ciertas entidades sagradas de carácter local, a las cuales siguen honrando con ofrendas y rezos ante las imágenes que de ellas colocan en los altares domésticos de sus residencias en Cancún, y a las que se encomiendan cotidianamente solicitando su protección.

El éxito alcanzado por quienes hace dos o tres décadas dejaron sus comunidades para irse a trabajar a la Riviera Maya sigue sirviendo de reclamo para que en la actualidad, un número importante de jóvenes ansiosos por conocer el mundo, decidan emprender el mismo camino. El problema, según cuentan los vecinos de las poblaciones visitadas, es que muchos de estos jóvenes salen sin ni siquiera haber concluido sus estudios y al llegar a sus lugares de destino descubren que sólo pueden aspirar a los trabajos peor remunerados. Así, no resulta extraño que muchos de ellos regresen pasados unos meses «con una mano delante y otra detrás», sin haber logrado sus objetivos de asentarse y procurarse un empleo estable que les permita mejorar su situación económica y la de sus familias. En los últimos años también ha contribuido de manera importante al regreso de migrantes que probaron suerte en Cancún, el notable incremento de la violencia y la inseguridad vinculada al narcotráfico y el crimen organizado que ha registrado las áreas urbanas del estado de Quintana Roo. En este sentido, y más allá de los datos oficiales que tratan de ocultar esta realidad para no afectar a la industria turística, fueron muchos los informantes que apuntaron hacia este factor como el detonante para regresar a sus comunidades, hastiados de presenciar en los barrios donde habitaban, antaño tranquilos, continuas peleas y asesinatos entre bandas rivales de narcos, además de padecer robos e incluso secuestros, que siempre quedan impunes cuando no son directamente amparados por la rampante corrupción que impera en los cuerpos y fuerzas de seguridad locales.

\section{A modo de colofón: impactos de la migración en las comunidades indígenas}

Actualmente es difícil encontrarse con alguna familia en las comunidades del municipio de Calkiní que no cuente con al menos uno de sus miembros trabajando fuera de la población. Al contrario, lo habitual es que varios de ellos salgan a diario o semanalmente para emplearse como albañiles, jardineros, mozos de almacén o empleadas domésticas, sobre todo en Mérida y en menor medida en Campeche; al tiempo que otros residen de manera permanente en Cancún u otros puntos de la Riviera Maya. Así, cada vez son menos las personas que optan por permanecer en sus comunidades y, menos aún, se dedican al tradicional cultivo de milpa de temporal, ya que desde hace varias décadas el imaginario colectivo tejido en torno al trabajo agrícola vincula a éste con la pobreza y el subdesarrollo endémico que históricamente han padecido la población nativa peninsular. Por consiguiente, en la actualidad ser campesino se 
considera sinónimo de pobreza; una pobreza que se identifica, a su vez, por una serie de rasgos característicos de las familias que tienen en la agricultura su principal fuente de ingresos, tales como el atuendo, el calzado o la pervivencia de la vivienda de tipo tradicional (elaborada a partir de maderas locales, barro y techo de palma), convertida en símbolo de precariedad frente a las casas de materiales de construcción al estilo urbano que han proliferado en los últimos años ${ }^{23}$.

A diferencia de lo que acontecía hasta hace tres o cuatro décadas, cuando hacer la milpa era una práctica habitual y distintiva de los habitantes de las comunidades rurales, e incluso quienes se marchaban a trabajar fuera pagaban a algún vecino para que éste se encargara de hacer sus milpas en su ausencia, en la actualidad cada vez son menos las personas que se dedican a esta actividad de manera exclusiva. Sin embargo, esto no significa que el trabajo en el campo esté desapareciendo sino que más bien ha modificado sus formas. Así, es habitual que los hombres por encima de los 35 años que han logrado hacerse de algún capital recurriendo al trabajo asalariado (habitualmente como maestros), inviertan en la adecuación de parcelas pertenecientes a las tierras ejidales comunitarias para convertirlas en pequeños ranchos ganaderos, donde crían hasta una docena de reses, o tras abrir pozos e instalar sistemas de riego se dediquen a la horticultura con fines comerciales. También es habitual que reserven una pequeña porción de sus terrenos para el cultivo de milpa de temporal, con la que obtener, al menos, algo de maíz, frijol, calabaza y chile para el consumo familiar. En estos casos los migrantes contratan a sus propios vecinos, campesinos que a su vez trabajan sus propios sembradíos pero que se emplean por días en la comunidad para obtener recursos en metálico, para que en su ausencia trabajen cuidando y vigilando sus parcelas ${ }^{24}$.

De esta forma, desde sus comienzos la migración permitió aumentar los flujos de económicos en el interior de las comunidades, pues la mayor parte del salario que obtienen los trabajadores regresa con ellos a sus poblaciones de origen los fines de semana. Lo anterior ha repercutido positivamente en las economías locales, fomentando la aparición de pequeños negocios y comercios de carácter familiar, abiertos en muchos casos gracias al dinero procedente del trabajo asalariado de alguno de sus miembros. También el consumo se ve beneficiado cada fin de semana con el retorno de los migrantes a sus comunidades de origen, pues es cuando sus mujeres aprovechan para adquirir aquellos bienes más apremiantes para el hogar y atender las

\footnotetext{
23 Una de las primeras cosas que hacen los migrantes cuando logran obtener un excedente monetario es invertirlo en la construcción de una vivienda de cemento y bloques en el terreno familiar. Habitualmente, el nuevo edificio se erige delante de la casa tradicional, quedando ésta oculta tras aquel. Estas viviendas fungen como símbolos del éxito económico alcanzado por el migrante ante la sociedad local, pero en muchos casos no son habitadas por resultar poco confortables ante el clima de extremo calor que se da durante casi todo el año en la Península. Así, son auténticas metáforas de los procesos de transculturización que se dan en las comunidades mayas donde, sobre todo los jóvenes, tratan de mostrarse «modernos» y occidentalizados en sus formas externas, aunque sigan siendo portadores, de forma oculta, de un sistema cosmogónico ancestral que es el que les permite dotar de significado al mundo que los rodea.

24 Jesús Lizama ha mostrado que esta es una práctica que habitual en otras áreas del ámbito peninsular indígena, por lo que visto así la migración favorece la circulación de dinero al interior de las comunidades y permite a aquellos que han optado por no abandonarlas para dedicarse a las tareas agrícolas hacerse de «recursos económicos para complementar sus necesidades básicas» (2007: 124).
} 
necesidades de sus hijos, así como para saldar las posibles deudas contraídas durante el transcurso de la semana en los comercios locales.

Pero no todo el dinero que llega en los bolsillos de los migrantes redunda en el beneficio de sus familias. Es norma habitual observar cómo cada sábado, a partir del mediodía, las numerosas cantinas y expendios de cerveza que existen en las comunidades trabajadas presentan una incesante concurrencia de varones de todas las edades que se reúnen a beber y emborracharse hasta bien entrada la noche. Si bien es cierto que el alcoholismo no constituye un fenómeno reciente en las poblaciones indígenas, lo cierto es que, según mis interlocutores, sí lo es el hecho de que cada vez a edades más tempranas los jóvenes comienzan a beber, merced al dinero que obtienen empleándose en las ciudades durante la semana. Ello provoca que hayan visto incrementarse los episodios de violencia y vandalismo protagonizados por jóvenes los fines de semana. A lo anterior se añaden otros problemas, derivados de los modelos y hábitos que adquieren en las ciudades algunos de estos jóvenes, como la adopción de prácticas y una estética propia de las pandillas urbanas, mismas que luego trasladan a sus comunidades de origen para ser imitados, a su vez, por otros jóvenes que buscan de esa forma distanciarse de los modelos «tradicionales» que consideran obsoletos, «atrasados» y marcadores de «pobreza», ubicados en las antípodas de los estereotipos de éxito basados en la ostentación de riqueza y el consumo conspicuo (Harris 1993: 32) que ofrecen a todas horas los medios de comunicación de masas. Como acertadamente ha señalado Lizama (2007: 125 y ss.), esta imitación de patrones de comportamiento «extraños» a la cultura maya denota una tácita aceptación de su supuesta superioridad con respecto a los que ya poseen y son propios de la tradición cultural nativa.

Así, renunciar a hablar la lengua maya, aunque la dominen por ser su lengua materna, por un español repleto de «malas palabras y groserías» es un claro ejemplo de cómo los jóvenes tratan de diferenciarse de sus mayores. Otro ejemplo lo encontramos en los diferentes patrones de consumo y estéticos que se han venido adoptando en las comunidades, más propio de las clases urbanas, y muy alejados de las formas de vida tradicionalmente austeras que aún caracterizan a las personas de mayor edad. Así, la música norteña de banda es la más escuchada hoy en día por los jóvenes, al tiempo que prefieren beber un refresco de cola en lugar del pozole preparado en casa. No son pocos los que visten con pantalones jeans cortos y anchos, al estilo cholo, y lucen tatuajes, piercings y peinados imposibles. Pero estos cambios no sólo se aprecian entre los jóvenes, aunque entre éstos están más generalizados. Hoy en día quienes pueden permitírselo se desplazan los fines de semana hasta Mérida o a Campeche para comprar ropa de marca, teléfonos celulares de última generación, artículos para el hogar o bienes suntuarios, como televisiones, equipos de música y electrodomésticos, e incluso para disfrutar de los tiempos de ocio familiar en las grandes plazas comerciales. Cada vez más, las bicicletas y los triciclos se están viendo sustituidos por ciclomotores y coches, e incluso por camionetas estilo pick up adquiridas en las concesionarias de las grandes ciudades. No deja de ser paradójico, en este sentido, que los migrantes indígenas funjan como una suerte de punta de lanza de un proceso de transfiguración étnica, en el cual adoptan y luego trasladan a sus comunidades de origen modelos y prácticas culturales característicos de las clases populares y mesti- 
zas urbanas, cuyos integrantes los rechazan y los consideran inferiores, precisamente, en función de su adscripción étnica ${ }^{25}$.

Para concluir, otro de los impactos que ha provocado el fenómeno migratorio en las comunidades indígenas, derivado de las mejoras en las condiciones económicas que experimentaron las familias con migrantes que vieron aumentar sus recursos monetarios gracias al acceso de éstos a trabajos asalariado más especializados, ha sido el surgimiento de una generación de jóvenes con un alto nivel de preparación académica. Así, en los últimos años comienza a ser habitual que los hijos de migrantes se trasladen durante la semana a alguna de las capitales peninsulares para cursar una licenciatura, normalmente de carácter técnico, y gracias al apoyo y a los recursos brindados por sus padres, estos jóvenes logren concluir sus estudios. Sin embargo, esta mejora evidente en las expectativas de futuro está trayendo aparejada consigo una nueva oleada migratoria protagonizada por estos nuevos licenciados, que sería interesante considerar en futuras investigaciones sobre el tema. Se trata de una migración mucho más «especializada» que la que protagonizan la mayoría de los indígenas, pero que vuelve a reeditar la necesidad de abandonar las comunidades rurales rumbo a las ciudades para un número cada vez mayor de jóvenes mayas con estudios superiores concluidos, que ven impotentes como para progresar en sus vidas deben dejar atrás a sus familias y amigos, pues ni siquiera en la cabecera municipal pueden encontrar trabajos acordes a su preparación. Así, ante la notable falta de desarrollo en las infraestructuras y en los servicios públicos en los que pudieran encontrar acomodo laboral, aunado al desinterés del sector privado por invertir en el desarrollo integral de los municipios y sus comunidad, las poblaciones indígenas están viendo alejarse a la que sin duda representa la generación mejor preparada que han visto crecer en su seno desde que pasaron a integrarse en la historia occidental. O lo que es lo mismo: asistimos a lo que podríamos considerar como una «fuga de cerebros», cuya preparación (y los sacrificios que ésta costó a las familias migrantes) no revertirá directamente en sus comunidades de origen. Sin duda, el penúltimo episodio del expolio que vienen padeciendo las poblaciones indígenas americanas desde hace más de 500 años.

Hasta aquí se ha tratado de ofrecer un bosquejo, a vuela pluma, de algunas de las aristas que presenta en las poblaciones nativas un tema tan complejo como el de la migración. Si bien es cierto que uno de los objetivos ha sido el de mostrar el carácter diacrónico de los movimientos demográficos de carácter laboral (especialmente hacia las ciudades) en un área habitada por la etnia maya peninsular, también lo es que se han dejado varias lagunas en las apreciaciones acerca de los cambios y reformulaciones que éstos están ocasionando en las poblaciones rurales en el presente. Sin embargo, y antes de concluir, quisiera hacer aquí una última reflexión a modo de epílogo, que pudiera quizá funcionar como cuestionamiento o crítica hacia alguno de los pensamientos que subyacen en las páginas anteriores. Si bien es cierto que los mayas de las comunidades

25 Lizama (2007: 126) explica este proceso de «transfiguración cultural» que viven los migrantes mayas en base a «la discriminación social existente en Yucatán», visible en la fuerte dicotomía indio-mestizo que pervive en la sociedad regional. Dicha dicotomía trasciende, incluso, las diferencias dentro de las mismas clases. Así, un maya puede ser igual de pobre que un no maya y compartir el mismo trabajo no cualificado, «pero los segundos se considerarán superiores a los primeros al concebirse ajenos a las costumbres de los pueblos mesoamericanos» (ibidem). 
trabajadas parecen prosperar cuanto más se separan del que podríamos considerar el patrón cultural tradicional indígena, y por ello optan por adoptar modelos exógenos a su cultura, también lo es que esta forma de insertarse en «la modernidad» es producto de la posición de subordinación que han padecido a lo largo de los últimos cinco siglos, tanto a nivel nacional como regional. Pese a la asimetría que existe en el presente entre estos dos mundos tan dispares pero profundamente interconectados, los miembros de la cultura maya siguen luchando por permanecer aunque para ello deban transformarse. Así, aunque la milpa se vea desplazada por el trabajo asalariado y muchos de los patrones tenidos por tradicionales hayan desaparecido o se hayan visto alterados, los hombres y mujeres mayas continúan exhibiendo formas particulares de relacionarse entre sí, con los «otros» y con el entorno que les rodea. Y en los resquicios de este interactuar cotidiano con el mundo es donde, por ejemplo, se esconden o camuflan, resignificados y reformulados, principios básicos de una cosmología nativa que pone en sintonía a los hombres y a los Yumtzilo'ob, dueños milenarios de los espacios y la naturaleza yucateca, bajo la práctica puntual de ciertos rituales que reeditan periódicamente la añeja reciprocidad que por siglos ha constituido el pilar sobre el que se sustentan las relaciones de los humanos con lo sagrado; una concepción de lo sagrado, eso sí, absolutamente holística, que permea la vida y la muerte; esto es: completamente maya.

Y si bien es cierto que hoy los mayas «gustan» la televisión a diario, consumen cocacola a raudales, se visten con tenis y playeras de marcas gringas y comen fast-food, también lo es, como ha subrayado Jesús Lizama, que los seres humanos somos libres de estar en el mundo e insertarnos en sus dinámicas de la forma que más nos convenga; y que «tan grave es discriminar al maya como compelerlo a permanecer como tal» (2007: 127). Así, no queda más que exigir y reclamar a los Estados respeto a la diferencia; un respeto que se traduzca en políticas públicas que permitan combatir de una vez por todas la pobreza y la marginación estructural que endémicamente han padecido las poblaciones indígenas, para que de esa forma, en los márgenes de una igualdad verdadera, los miembros de los pueblos originarios de la península de Yucatán puedan decidir, por sí mismos, sus propias opciones de supervivencia. Mientras este acto de justicia social básico acontezca, la cultura maya seguirá, como desde hace siglos, haciendo gala de su milenaria plasticidad, modificándose para perdurar en el tiempo.

Agradecimientos: La realización de este trabajo se enmarca en el proyecto colectivo «Historias de migración en Campeche», el cual se desarrolló entre 2014 y 2015 con la financiación del Programa de Apoyo a Proyectos de Investigación e Innovación Tecnológica (PAPIIT IA400214-2) de la UNAM. Agradezco a la responsable académica del proyecto, la Dra. Rosa Torras Conangla, haberme invitado a participar en él y la posibilidad que ello me brindó para establecer vínculos entre la historia y la etnografía.

\section{Referencias bibliográficas}

BARTOLOMÉ, Miguel Alberto

2006 Gente de costumbre y gente de razón. Las identidades étnicas en México. México: Siglo XXI Editores. 
Bracamonte y Sosa, Pedro y Gabriela Solís Robleda

1996 Espacios mayas de autonomía. El pacto colonial en Yucatán. Mérida: Universidad Nacional Autónoma de Yucatán y Consejo Nacional de Ciencia y Tecnología.

CÁRDENAS MÉNDEZ, Eliana

2013 «De dinámicas migratorias a biografías ingrávidas en la Riviera Maya», en Entre irse y quedarse... Estructura agraria y migraciones internas en la Península de Yucatán, Jesús Lizama, coord., pp. 183-207. México: Editorial Letra Antigua.

Daltabuit Godás, Magalí

2009 «Turismo y migración en el mundo maya», en Diásporas, migraciones y exilios en el mundo maya, Mario H. Ruz, Joan García Targa y Andrés Ciudad, eds., pp. 275-288. México: Sociedad Española de Estudios Mayas, CEPHCIS, UNAM.

FARRISS, Nancy M.

2012 La sociedad maya bajo el dominio colonial. México: CONACULTA, INAH, Artes de México.

GeErTz, Clifford

2005 La interpretación de las culturas. Barcelona: Editorial Gedisa.

HARRIS, Marvin

1993 Jefes, cabecillas, abusones. Madrid: Alianza Editorial.

LACADEna, Alfonso y Andrés Ciudad Ruiz

2009 «Migraciones y llegadas: mito, historia y propaganda en los relatos mayas prehispánicos en las tierras mayas», en Diásporas, migraciones y exilios en el mundo maya, Mario H. Ruz, Joan García Targa y Andrés Ciudad, eds., pp. 57-78. México: Sociedad Española de Estudios Mayas, CEPHCIS, UNAM.

LEWIN FISCHER, Pedro

2008 «Yucatán: región migratoria emergente», en Caminantes del Mayab. Los nuevos migrantes de Yucatán a los Estados Unidos, Wayne A. Cornelius, David Fitzgerald y Pedro Lewin Fischer, coords., pp. 21-54. Mérida: Instituto de Cultura de Yucatán, INAH, CONACULTA.

Lizama QuiJano, Jesús

2007 Estar en el mundo. Procesos culturales, estrategias económicas y dinámicas identitarias entre los mayas yucatecos. Mérida: CIESAS, Editorial Miguel Ángel Porrúa.

Machuca Gallegos, Laura

2010 «Relaciones entre los propietarios y los indígenas en las haciendas yucatecas del siglo XIX», en El pueblo maya y la sociedad regional, Jesús Lizama, coord., pp. 83-113. México: CIESAS, Universidad de Oriente.

OKoshí Harada, Tsubasa

2009 «Introducción», en Códice de Calkiní, Tsubasa Okoshí introducción, transcripción, traducción y notas, pp. 5-29. México: Centro de Estudios Mayas, Instituto de Investigaciones Filológicas, UNAM.

Peniche Moreno, Paola

2009 «Migraciones y supervivencia. Las mayas ante las hambrunas en el Yucatán colonial», en Diásporas, migraciones y exilios en el mundo maya, Mario H. Ruz, Joan García Targa y Andrés Ciudad, eds., pp. 189-206. México: Sociedad Española de Estudios Mayas, CEPHCIS, UNAM. 
Quezada, Sergio

1993 Pueblos y caciques yucatecos. 1550-1580. México: El Colegio de México.

Quintal Avilés, Ella, Juan Ramón Bastarrachea, Fidencio Briceño, Martha Medina, Renée Petrich, Lourdes Rejón, Beatriz Repetto y Margarita Rosales

2003 «Solares, rumbos y pueblos: organización social de los mayas peninsulares», en La comunidad sin límites. La estructura social y comunitaria de los pueblos indígenas de México, vol. I, Saúl Millán y Julieta Valle, coords., pp. 293-382. México: INAH.

RAMÍREZ CARRILlo, Luis Alfonso

2002 «Yucatán», En Los mayas peninsulares: un perfil socioeconómico, Mario H. Ruz, coord. pp. 47-77. México: Centro de Estudios Mayas, Instituto de Investigaciones Filológicas, UNAM.

Ruz SosA, Mario Humberto

2002a «Los mayas peninsulares», en Los mayas peninsulares: un perfil socioeconómico, Mario H. Ruz, coord. pp. 10-45. México: Centro de Estudios Mayas, Instituto de Investigaciones Filológicas, UNAM.

2002 b «Credos que se alejan, religiosidades que se tocan», en Religión maya, Mercedes de la Garza y Martha Ilia Nájera, eds., pp. 321-363. Madrid: Editorial Trotta.

2006 Pueblos indígenas del México contemporáneo. Los mayas, vol. 2, México: Comisión Nacional para el Desarrollo de los Pueblos Indígenas / Programa de las Naciones Unidas para el Desarrollo.

Ruz Sosa, Mario Humberto (coord.)

2007 El Campeche maya. Atisbos etnográficos. Mérida: Unidad Académica de Ciencias Sociales y Humanidades, Coordinación de Humanidades, UNAM.

SiERra Sosa, Ligia

2009 «Cancún y la Riviera Maya: migración y turismo», en Diásporas, migraciones y exilios en el mundo maya, Mario H. Ruz, Joan García Targa y Andrés Ciudad, eds., pp. 289-308. México: Sociedad Española de Estudios Mayas, CEPHCIS, UNAM.

Sierra Sosa, Ligia y Bonnie CAmpos CÁmara

2013 «Turismo, migración y vulnerabilidad social en la Costa Maya de Quintana Roo», en Entre irse y quedarse... Estructura agraria y migraciones internas en la Península de Yucatán, Jesús Lizama, coord., pp. 183-207. México: Editorial Letra Antigua. 